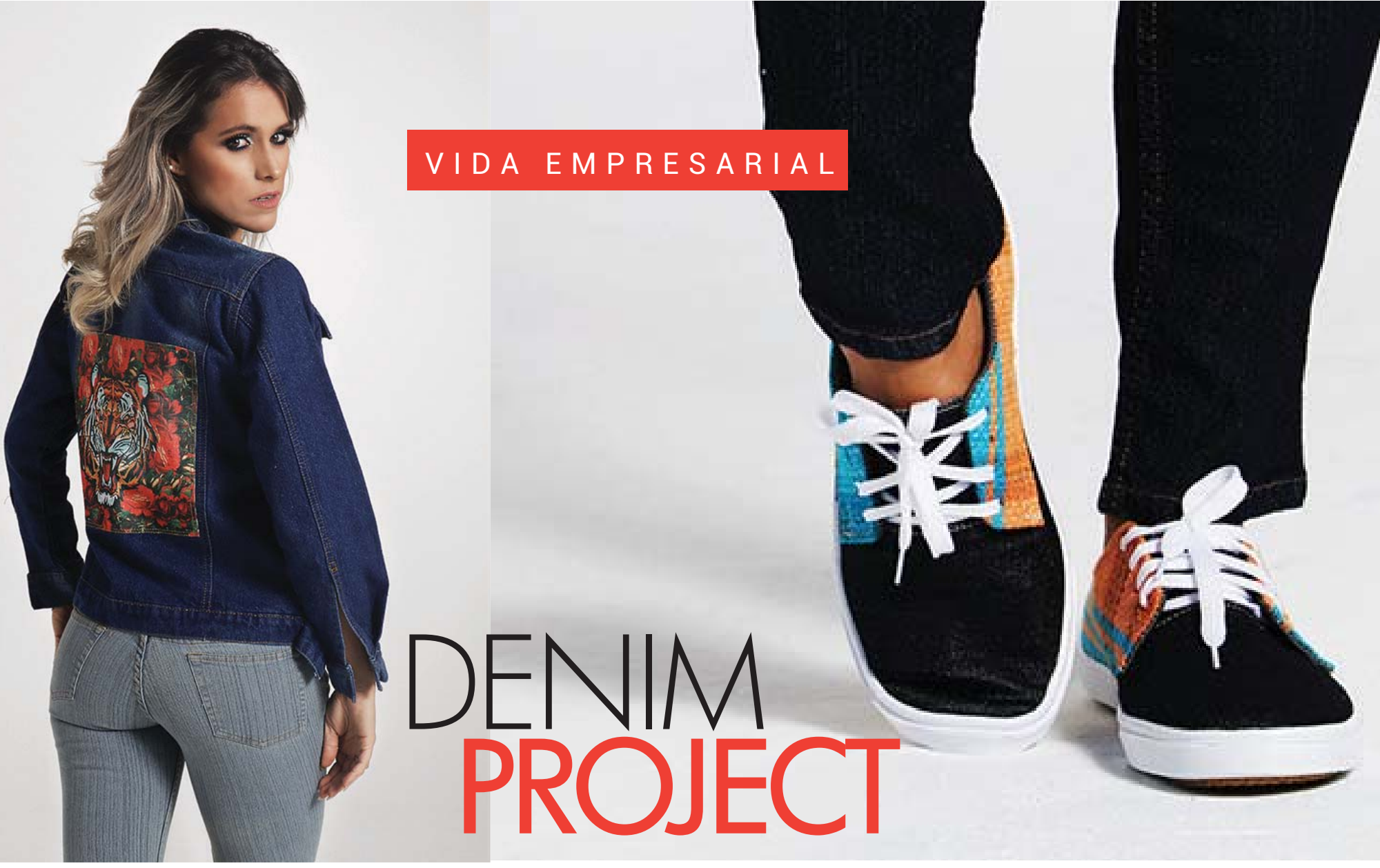

\section{Marca que busca generar impacto social y ambiental a través de la moda}

Por Cecilia Rivera Ingeniero y Master en Mercadeo Catedrático de la Universidad Centroamericana José Simeón Cañas

Entrevista a Adriana Corcios y Roberto Ticas

\section{1. ¿Qué significa Denim Project y cómo surgió la idea?}

Roberto Ticas, de 29 años y administrador de empresas, constituyó su propia marca productora y diseñadora de Jeans a partir de la experiencia adquirida en su empresa familiar. Asi nace Denim Project apoyado en un negocio familiar en sus inicios.

Él necesitaba un socio o mano derecha que le ayudara y apoyara en el proyecto, asociándose con su amiga Adriana Portillo de 24 años también administradora de empresas.

El Denim es la palabra en inglés para definir el tipo de tela con la que se fabrican los jeans. En nuestra región es mejor conocida como "lona "o "mezclilla". El material se originó en el sur de Francia, en la localidad de Nimes de ahí el origen de la palabra ( la tela De Nimes $=$ Denim $)$.

La palabra Project hace referencia a la razón de ser de la marca que busca generar impacto social y ambiental a través de la moda apoyando diversas causas y proyectos.

Entre sus principales productos hay gorras, zapatos, camisas, chaquetas, maletines y portalaptos, la materia prima es importada, "en la confección del jeans, el denim se importa de Estados Unidos, Brasil, Japón porque no se produce en el país.

\section{2. ¿A qué se refieren cuando dicen que su empresa busca un impacto social y ecológico en El Salvador?}

Cuando se comenzó este emprendimiento lo primero que pensamos fue crear una idea de negocio que nos permitiera generar un impacto positivo en nuestro país, afirma Roberto.

Escoger el rubro de la moda se dio de manera natural pues Roberto tenía experiencia en producción del jeans y Adriana tenía mucho talento para diseñar.

La tarea más difícil fue encontrar un modelo de negocio que nos permitiera lograr este objetivo.

\section{Rápidamente nos dimos cuenta de cuatro cosas:}

1. El jeans sigue siendo la prenda más utilizada en el mundo ( 2000 millones de jeans se venden al año en todo el mundo y un mercado de 60 billones de dólares.

2. La gente sigue consumiendo muchos jeans pero la mayoría de marcas ofrecen siempre lo mismo. El consumidor actual aprecia una marca que logre destacar por hacer las cosas diferentes. 


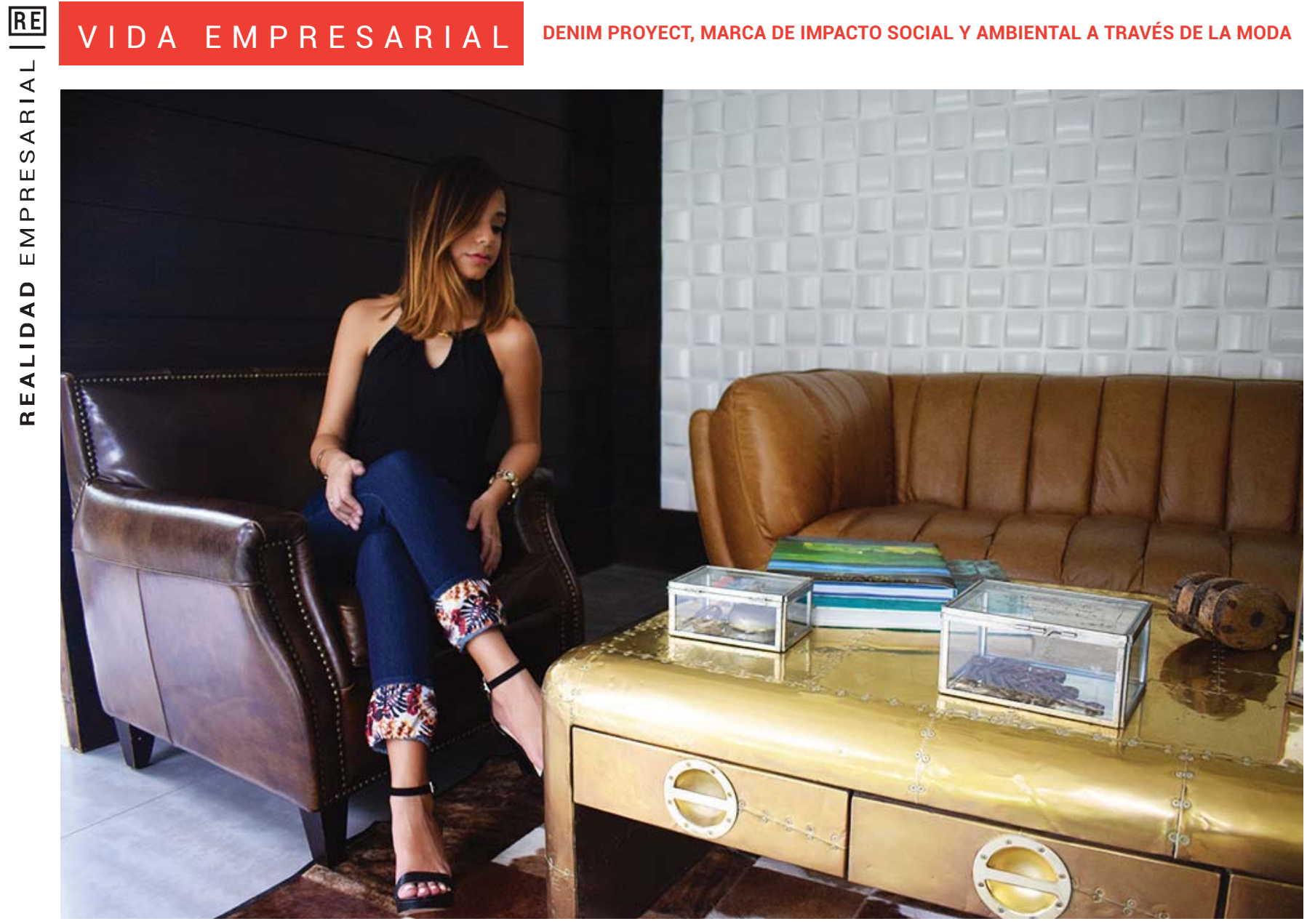

3. Un jeans consume 9000 litros de agua para producirse. Si hacemos la mutiplicación entenderemos que es una industria que consume DEMASIADA AGUA ... un recurso cada vez más escaso.

4. Las condiciones laborales de la industria textil son malas y los salarios son muy bajos.

Después de muchos meses de buscar cómo solucionar todas estas problemáticas con un solo producto decidimos crear jeans con diseños diferentes (reversibles y con aplicaciones) que en su fabricación incluirán comunidades vulnerables y métodos de producción más amigables con el medio ambiente. Comenzamos entonces a trabajar en sistemas de reutilización y purificación de agua, calderas de bio masa y materiales reciclados para crear nuestras prendas.

Creamos los primeros jeans hechos a bases de botellas recicladas de la región centroamericana.

Finalmente, con cada colección buscamos apoyar una causa o proyecto que tenga que ver con la protección del medio ambiente o el desarrollo de la sociedad en general.

\section{3. ¿Cuál ha sido la respuesta de los} consumidores ante la compra de las diversas colecciones de ropa que han lanzado hasta ahora?

Cuando comenzamos con esto nunca creímos que creceríamos tan rápido. Sacamos unas cuantas piezas al principio y nos presentamos en una plataforma de emprendedores llamada "El Mercadito". Nos presentamos con unos jeans reversibles muy originales, pues no sólo queríamos generar una propuesta de valor diferente en cuanto a procesos productivos sino también en cuanto a diseño, afirma Adriana.

Creamos los primeros jeans reversibles de la región y fue una sorpresa la acogida del producto. A partir de ahí seguimos mejorando el producto y continuamos diseñando nuevo diseños y nuevas prendas. Diseñamos los primeros jeans hechos a base de botellas recicladas. Hoy en día tenemos jeans (8 estilos diferentes y más de 15 acabados), shorts, chaquetas Denim , camisetas, gorras y camisas de vestir. Realmente hemos tenido una muy buena acogida comentó Roberto.

\section{4. ¿Sus colecciones son inspiradas en algún diseñador o son totalmente originales?}

Creemos en un modelo de negocio colaborativo . Queremos ser una plataforma para ilustradores y diseñadores que quieran ver su arte plasmado en ropa. Nuestras colecciones las hemos trabajado con ilustradores y diseñadores salvadoreños. Nos encanta poder trabajar y compartir con diferentes artistas a la hora de diseñar.

La última colección estuvo a cargo de Ernesto Rodríguez (Neto Rod ) y la que se viene está a cargo de los chicos de Virgin Tattoo Studios, expresa Adriana. 


\section{5. ¿Tienen algún plan de exportación de su producto en el futuro?}

Nuestro plan de negocio está pensado para exportación. Sin embargo, estamos en una fase de desarrollo temprana y le estamos enfocados principalmente en el posicionamiento de la marca.

Debemos fortalecer nuestra estructura y nuestra imagen localmente primero antes de poder cruzar fronteras. Hemos tenido la oportunidad de visitar varios países con la marca (Estados Unidos, Costa Rica, Panamá, México y Guatemala) y en todas hemos logrado capturar el interés de distribuidores e inversionistas. Eso nos da la tranquilidad de que estamos haciendo algo bien, sin embargo no está en nuestros planes expandirnos a otros países este año.

El sueño de Denim Project es el poder ser la marca textil referente en el país para las personas que quieran iniciar su proyecto y que su marca esté enfocada en lo social y lo ecológico.

El objetivo a largo plazo es tener nuestra propia tienda con los productos para vestir completamente a la persona (camisa, jeans, gorra). Creemos que la empresa puede llegar a ser mucho más, poner tiendas en otros países", expresa Adriana Portillo.

\section{6. ¿Adónde se pueden encontrar sus productos en El Salvador?}

Actualmente tenemos presencia en 8 tiendas con productos específicos en cada una.

JEANS DE DAMA: Mia Voga, April Store, Fandango y La Casa Tomada.

CAMISETAS Y GORRAS: Hecho en Casa, Tienda Cabal y La Casa Tomada, Aeropuerto de El Salvador y Cadejo.

JEANS DE CABALLERO: Hecho en Casa y La Casa Tomada CAMISAS DE VESTIR: Hecho en Casa, Cabal y La Casa Tomada.

A DOMICILIO: FACEBOOK con entregas a domicilio o en tiendas Cabal y La Casa Tomada. 